\title{
ENSAIO DE ADUBAÇÃO N-P-K EM AMENDDOIM(*)
}

H. Gargantini, engenheiro-agrônomo, Seģão de Fertilidade do Solo, ROMEU DE TELLA, engenheiro-agrônomo, Seção de Oleaginosas a A. ConAGIN, engenheiroagrônomo, Seção de Técnica Experimental, Instituto Agronômico

\section{RESUMO}

O presente ensaio, conduzido em vasos de Mitscherlich contenda terro-roxamisturada, foi instalado com a finalidade de se determinar o efeito dos elementos fertilizantes nitrogênio, fósforo e potássio, na produçc̃o do amendoim. Empregou-se para êste estudo o delineamento fatorial $3 \times 4 \times 3$, contendo cada tratamento três repetições. Foram colhidos separadamente a parte aérea e os frutos e sôbre êstes dois fatôres foi estudada a açāo daqueles elementos fertilizantes. Os dados coletados mostram haver semelhança entre os resultados com a produção da parte aérea e a dos frutos.

O elemento responsável pela maior produção foi o fósforo, vindo a seguir o nitrogênio; o potássio não teve influência no aumento de produção. Pelos dados obtidos neste experimento deduz-se que a fórmula de adubação que melhores resultados apresentou foi a $\mathrm{N}_{1} \mathrm{P}_{3}$, ou sejam, 30 e 240 quilos de $\mathrm{N}$ e $\mathrm{P}_{2} \mathrm{O}_{5}$ por hectare, respectivamente.

\section{1 - INTRODUÇÃO}

O amendoim (Arachis hypogaea, L.) ocupa uma posição de destaque.entre as mais importantes culturas de interêsse econômico, graças ao grande e variado número de aplicações que oferece.

A maior parte da produção de amendoim é empregada na indus. trialização do óleo, seu principal produto; a outro é consumida "in natura", no preparo de confeitos, manteiga etc.

O óleo tem larga aceitação na alimentação humana dada a sua alta digestibilidade, sendo ainda usado para fins industriais e medicinais. O consumo de óleo de amendoim em São Poulo tem aumentado consideràvelmente nestes últimos anos, provocando, dêste modo, grande interêsse dos lavradores pelo cultivo desta oleaginosa.

(*) Trabalho apresentado no VI Congresso Brasileiro De Ciêncio Do Solo, realizado em Salvador, Bahia, de 15 a 26 de julho de 1957.

Recebido para publicação em 12 de outubro de 1957. 
O Instituto Agronômico vem, há longos anos, estudando os problemas relacionados com esta cultura, tendo já resolvido satisfatòriamente aquêles que dizem respeito a variedades, solos, épocas de plantio, espaçamento etc. Todavia, com relação à adubação, as experiências até agora realizadas não apresentaram resultados conclusivos (6), razão pela qual tem-se aconselhado o plantio do amendoim em áreas antes ocupadas pelo algodão ou milho. Dêsse modo êle se beneficia do efeito residual dos adubos aplicados àquelas culturas, ao mesmo tempo que se procede à exploração racional do solo.

Não é apenas entre nós que os resultados com a adubação dessa cultura têm sido contraditórios, e as opinióes de diversos autores, a respeito, são as mais desencontradas.

Gore (4), em experiências conduzidas com amendoim da variedade Spanish, diz que encontrou melhor reação quando aplicou cêrca de $450 \mathrm{~kg} / \mathrm{ha}$ de uma fórmula completa $6-6-6$, para $\mathrm{N}, \mathrm{P}_{2} \mathrm{O}_{5}$ e $K_{2} O$. Já para as variedades do țipo Runner não encontrou reação para o nitrogênio, caso em que recomenda cêrca de $170 \mathrm{~kg} / \mathrm{ha}$ de superfosfato e $56 \mathrm{~kg} / \mathrm{ha}$ de cloreto de potássio.

Beattie, Poos e Higgins (1) afirmam que embora o amendoim seja leguminosa capaz de fixar o nitrogênio do ar atmosférico, esgota o solo. Assim, uma cultura produzindo cêrca de 1000 quilos de amendoim descascado e 2000 quilos de feno, retira cêrca de 65 quilos de nitrogênio, 11 quilos de fósforo, 50 quilos de potóssio e 40 quilos de cálcio. Pràticamente tôda a planta, com exceção de poucas raízes, é removida do terreno para aí não mais retornar. Mostram que as fórmulas de adubação do amendoim geralmente são feitas na base de pouco nitrogênio, bastante fósforo e pouco potássio. Apresentam, ainda, uma série de fórmulas usuais em diversos Estados americanos, e terminam dizendo que o comum, nesses Estodos, é o emprêgo de fórmulas ricas nos elementos nutritivos para as culturas precedentes; - amendoim é plantado a seguir, sem receber adubação alguma, ou se a recebe, o é em quantidades muito pequenas.

Um ponto de vista interessante é o citado por York e Colwell (8), quando comentam o fato de o amendoim extrair grandes quantidades de elementos nutritivos do solo e quase nunca reagir às adubações; dizem êles: "as leis físicas e químicas que governam a absorção e utilização dos elementos fertilizantes pelo amendoim, não devem ser as mesmas que para as outras plantas". Citam os trabalhos de Brady, Reed e Colwell, os quais recomendam, como meios de obter os maiores 
benefícios com o uso de fertilizantes, a aplicação dêstes na zona de formação dos frutos e não pròpriamente na zona de localização das raízes. Outro ponto que pode prejudicar sobremaneira a cultura, é a colocação das sementes em contato direto com os fertilizantes por ocasião do plantio.

Rodrigo (5) acha que um fertilizante comercial rico em fósforo e potássio e com pouco nitrogênio é preferível quando aplicado à razão de 300 a 500 quilos por hectore. Diz ainda o mesmo autor que devido às raízes do amendoim não se espalharem muito fora das linhas, os fertilizantes devem ser colocados no sulco e abaixo das sementes, por ocasião do plantio.

Souza e Canecchio (6) recomendam os solos arenosos como os que melhor se prestam para esta cultura. As terras-roxas-misturadas também podem ser exploradas, não obstante o produto não apresentar bom aspecto, devido à coloração do fruto. O amendoim prefere solos leves, de pouca acidez, bem drenados e que não se encharquem com as chuvas.

Iniciando novos estudos relativos à adubação do amendoim, instalou-se êste ensaio, em vasos de Mitscherlich, para verificação do efeito do nitrogênio, fósforò e potássio sôbre essa cultura.

Se bem que os resultados aqui obtidos não possam ser levados imediatamente à grande cultura, êles fornecem informações básicas que não podem ser prontomente obtidas com a experimentação de campo e acêrca das necessidades da planta com relação aos elementos nutritivos. Além de seu baixo custo, a experimentação em vasos apresenta as vantagens de se poder eliminar as variações da fertilidade inerentes ao próprio solo, e de se poder controlar as influências dos outros fatôres que agem sôbre o desenvolvimento das plantas, de tal modo que apenas as influências dos elementos nutritivos se façam sentir.

\section{2 - MATERIAL E METODO}

O solo utilizado neste ensaio foi o do tipo terra-roxa-misturada, proveniente da Estação Experimental Central do Instituto Agronômico, em Campinas. Foi coletado à profundidade de $0-15 \mathrm{~cm}$, sêco ao ar, muito bem homogeneizado e passado através de uma peneira de $2 \mathrm{~mm}$ de abertura de malha. 
Sua análise apresentou as seguintes características físico-químicas:

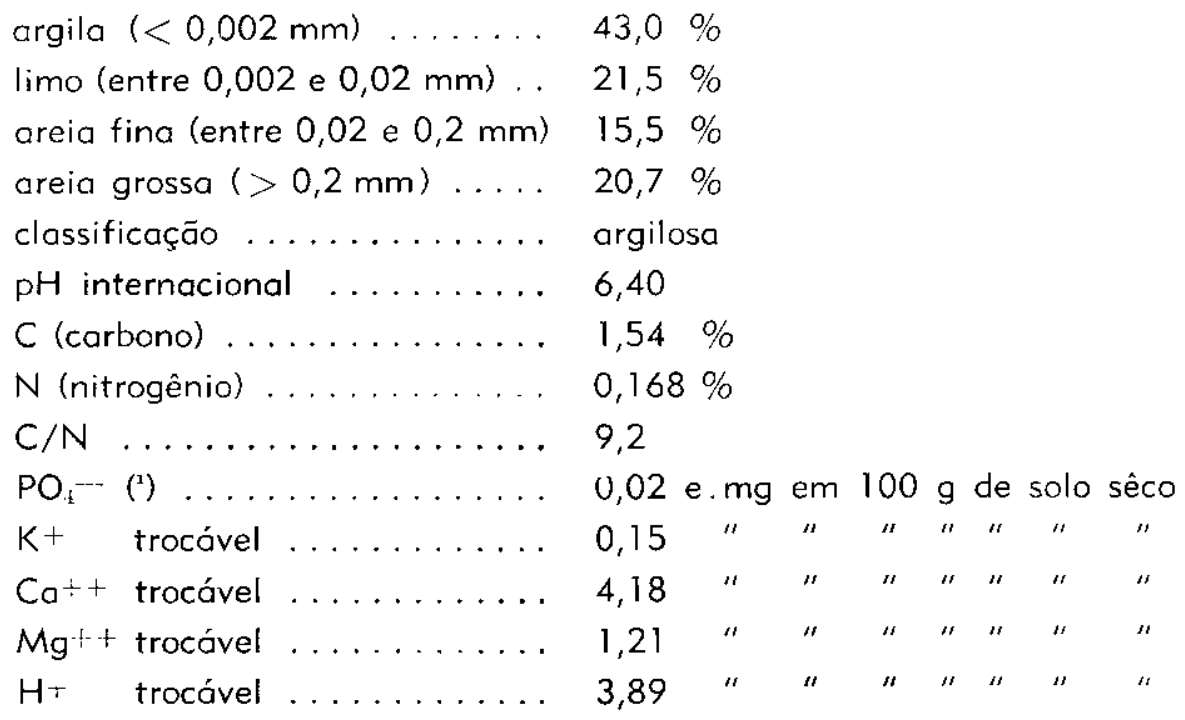

A variedade de amendoim empregada foi a Tatuí - 76 (2). Essa variedade, originária dos Estados Unidos da América do Norte e aqui introduzida em 1941, foi lançada em substituição à variedade Tatu - 53 e vem sendo bem aceita pelos lavradores do Estado, devido à sua produtividade e bom teor em óleo.

Os fertilizantes utilizados foram prèviamente analisados e apresentaram a seguinte composição: nitrocálcio, $20,3 \%$ de $N_{\text {; }}$ superfosfato, $21,8 \%$ de $\mathrm{P}_{2} \mathrm{O}_{5}$; e cloreto de potássio, $60,3 \%$ de $\mathrm{K}_{2} \mathrm{O}$.

As doses dos elementos empregados, assim como as quantidades em quilos por hectare, foram as da seguinte relação.
Dose
$N$
$\mathrm{P}_{3} \mathrm{O}_{3}$
$K_{z} O$

$\begin{array}{ccccccc} & g / v a s o & k g / h a & g / m a s o & h g / h a & g / v a s o & k g / h n \\ 1 & 0,12 & 30 & 0,24 & 60 & 0,12 & 30 \\ 2 & 0,24 & 60 & 0,48 & 120 & 0,24 & 60 \\ 3 & - & - & 0,96 & 240 & - & -\end{array}$

(1) $\mathrm{PO}_{1}{ }^{--}$-extraído com soluçäo $0,05 \mathrm{~N}$ de $\mathrm{H}_{2} \mathrm{SO}_{4}$. 
Empregou-se para êste ensaio o delineamento fatorial $3 \times 4 \times 3$, contendo cada tratomento três repetições.

$O$ ensaio foi conduzido em vasos de Mitscherlich, de ferro esmaltado, com capacidade para seis quilos de terra, na estufa central do Instituto Agronômico.

O preparo foi feito colocando-se aproximadamente $3 \mathrm{~kg}$ de terra nos vasos, aos quais foram misturados os fertilizantes; em seguida juntou-se mais terra até completor o pêso de $5 \mathrm{~kg}$. $O$ plantio se deu em 7 de novembro de 1956, usando-se 10 sementes por vaso. Estas germinaram a 11 do mesmo mês, tendo sido feito um desbaste 15 dias após, deixando-se três plantinhas por vaso. Por ocasião da floração, juntou-se a cada vaso mais um quilo de terra, para fazer a amontoa. Os vasos foram mantidos com umidade favorável até a formação das vagens, quando então a quantidade de água foi bastante reduzida, até ser totalmente suspensa quando se aproximou a colheita. Todo o líquido percolado foi retornado aos vasos, de acôrdo com a técnica recomendada por Mitscherlich.

As sementes utilizadas foram prèviamente tratadas com Uspulum, e durante o ciclo da planta foram feitas três pulverizações com Lindane a $28 \%$, empregando-se $20 \mathrm{ml}$ em 10 litros de água em cada pulverização e para todos os vasos.

Em 3 de abril de 1957 procedeu-se à colheita, cortando-se a parte aérea bem rente ao solo, sendo a seguir picada, sêca a $60^{\circ} \mathrm{C}$ e pesada. As vagens foram colhidas separadamente, limpas da terra que porventura estivesse aderente, sêcas também a $60^{\circ} \mathrm{C}$ e a seguir pesadas.

\section{3 - RESULTADOS E DISCUSSÃO}

No estudo do efeito dos fertilizantes nitrogenados, fosfatados e potássicos, consideraram-se os pesos da parte aérea e a produção de frutos.

A parte vegetativa do amendoim possui grande valor no alimentação animal e é muito utilizada para êsse fim. Outro emprêgo muito comum é a sua utilização como matéria orgânica para ser incorporada ao solo, após a colheita dos frutos.

No quadro 1 estão os resultados relativos à parte aérea das plantas. 
Quadro 1. - Resultodos obtidos com o pêso sêco $\left(a 60^{\circ} \mathrm{C}\right.$ ) da parte aérea e dos frutos, nos diferentes tratamentos. Os dados referem-se à média obtida em três vasos

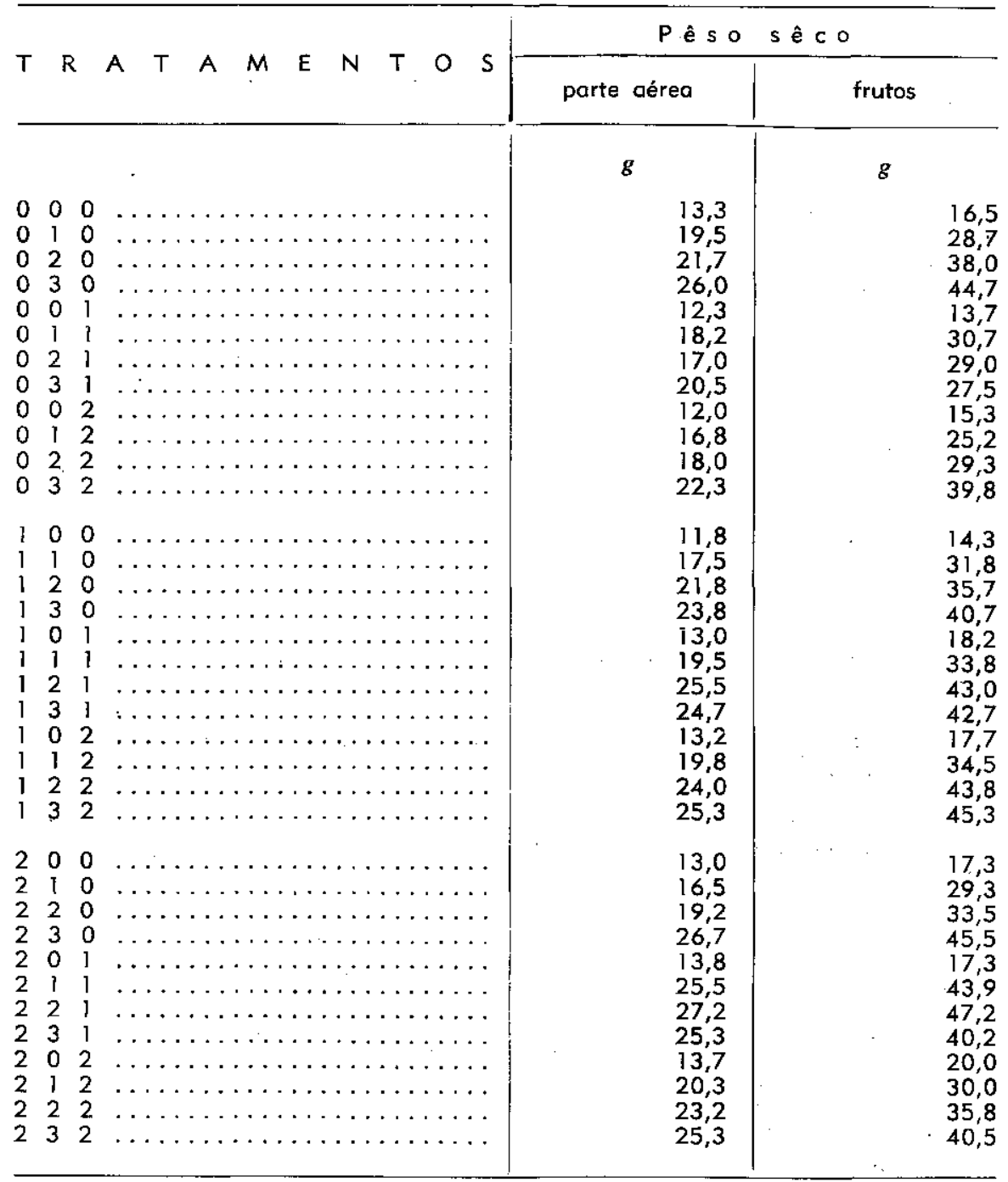

Pelos resultados, pode-se verificar que o elemento fertilizante que maior produção imprimiu foi o fósforo. A análise da variância apresentada no quadro 2, mostrou serem significativos os efeitos linear e quadrático dêsse elemento. 
QUADro 2. - Análise da variância para o pêso da parte aéreo, colculada na base de um vaso

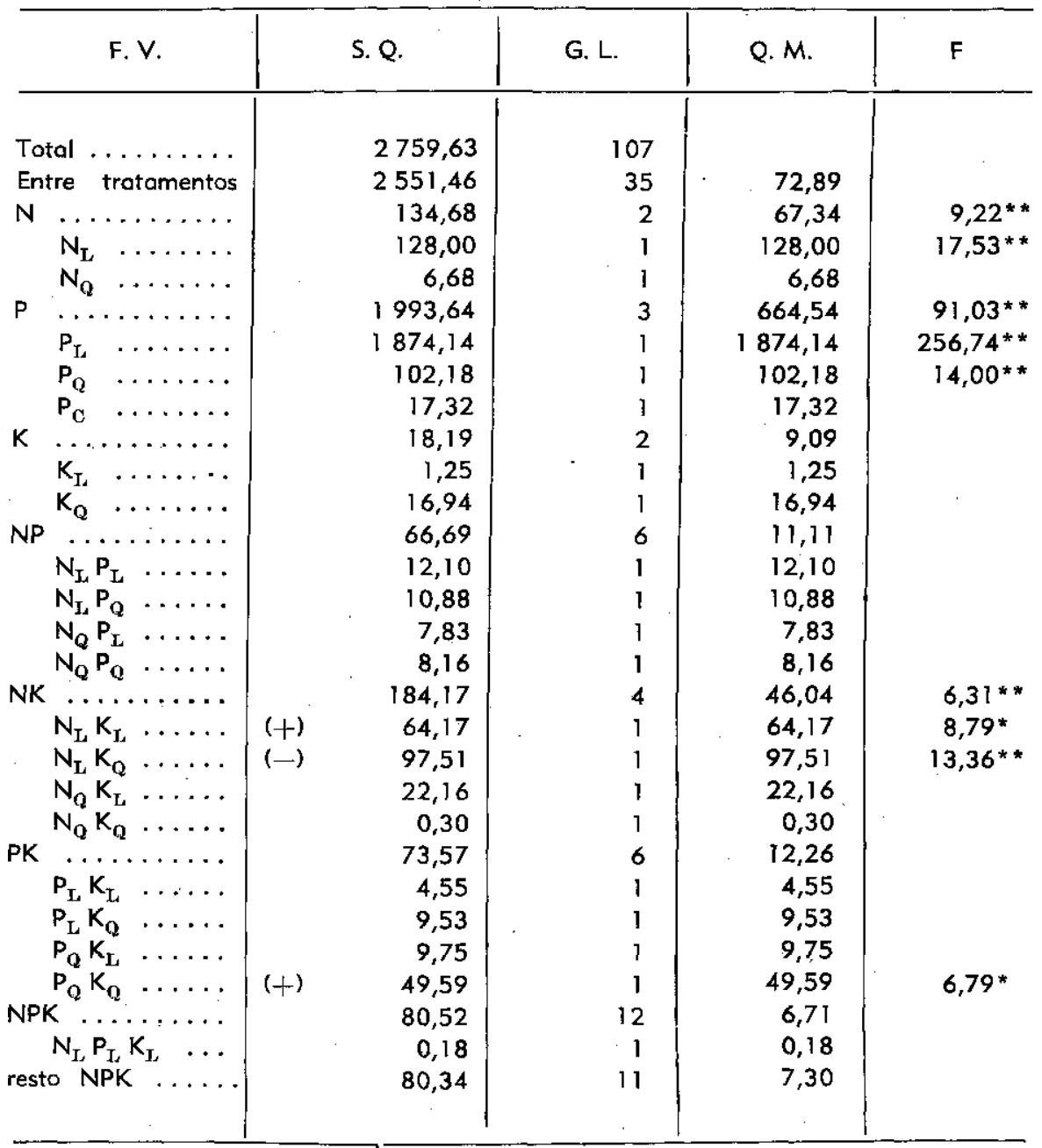

Para o nitrogênio verificou-se que sòmente o componente linear foi significativo.

O potássio, ao contrário, não teve influência na produção de massa verde.

A interação $\mathrm{N} \mathrm{K}$ foi significativa a $1 \%$ e a $N$ P não foi significativa. Da interação $N K$, os componentes $N_{L} K_{L}$ e $N_{L} K_{Q}$ foram 
significativos. Dos componentes da interação $P K$, sòmente $P_{Q} K_{2}$ foi significativo.

$\mathrm{Na}$ figura 1 é apresentado gràficamente o aumento obtido na parte aérea, com o emprêgo dos fertilizantes citados.

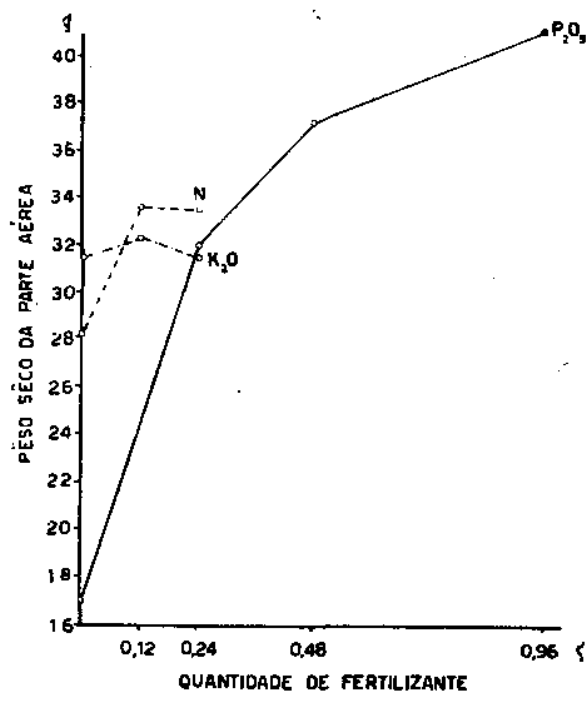

Figura 1. - Produçōes médias, por vaso de Mitscherlich, em gramos de material sêco do parte aérea, obtidas em função das doses dos elementos $\mathrm{N}$, $\mathrm{P}_{2} \mathrm{O}_{\bar{v}}$ e $\mathrm{K}_{2} \mathrm{O}$ empregadas.

A anólise da variância registrada no quadro 3 , mostrou que o elemento que melhor atuou foi o fósforo, sendo os componentes linear e quadrático significativos. A curva que melhor explica êste efeito é um polinômio do $2 .^{\circ} \mathrm{grau}$, conforme mostra a figura 2 .

York e Colwell (8), fazendo uma revisão bibliográfica dos trabalhos com amendoim em diferentes partes do mundo citam Baten, Ferris, Moses, Selschop, Krauss e outros, os quais afirmam que o maior aumento obtido na cultura do amendoim advém da aplicação de fósforo ao solo, resultados idênticos ao aqui encontrado.

Para o nitrogênio, sòmente o componente linear foi significativo: o quadrático quase chegou a ser significativo. Pràticamente, o máxime de produção foi obtido com a dose 1 . A curva da figura 2 mostra êste fato. 
Quadro 3. - Análise da variância para o pêso de amendoim, calculada na base de um vaso

\begin{tabular}{|c|c|c|c|c|}
\hline F. V. & S. Q. & G. L. & Q. M. & $F$ \\
\hline Total ......... & 12074,80 & 107 & & \\
\hline Entre tratamentos & 11541,95 & 35 & & \\
\hline$N \ldots \ldots \ldots \ldots$ & 647,70 & 2 & 323,85 & $8,13^{* *}$ \\
\hline $\mathbf{N}_{\mathbf{L}} \ldots \ldots \ldots$ & 477,92 & 1 & 477,92 & $11,99 * *$ \\
\hline $\mathrm{N}_{\mathrm{Q}} \ldots \ldots \ldots$ & 169,77 & 1 & 169,77 & 4,26 \\
\hline$P \quad \ldots \ldots \ldots \ldots$ & 9094,50 & 3 & 3031,50 & $76,07^{* *}$ \\
\hline $\mathrm{P}_{\mathrm{L}} \quad \ldots \ldots \ldots$ & 8073,60 & 1 & 8073,60 & $202,60 * *$ \\
\hline $\mathrm{P}_{\mathrm{Q}} \ldots \ldots$ & 930,45 & 1 & 930,45 & $23,35^{* *}$ \\
\hline$P_{\mathrm{C}} \ldots \ldots$ & 90,45 & 1 & 90,45 & \\
\hline $\mathrm{K} \ldots \ldots \ldots \ldots$ & 17,35 & 2 & 8,67 & \\
\hline$K_{L} \quad \ldots \ldots$ & 0,125 & 1 & 0,125 & \\
\hline $\mathrm{K}_{\mathbf{Q}} \ldots \ldots$ & 17,22 & 1 & 17,22 & \\
\hline NP $\ldots \ldots \ldots \ldots$ & 129,65 & 6 & 21,60 & \\
\hline$N_{I} P_{I}, \ldots \ldots$ & 7,65 & 1 & 7,65 & \\
\hline$N_{L} P_{Q} \ldots \ldots$ & 31,33 & 1 & 31,33 & \\
\hline$N_{Q} P_{I} \ldots \ldots$ & 50,05 & 1 & 50,05 & \\
\hline$N_{Q} P_{Q} \ldots \ldots$ & 27,80 & 1 & 27,80 & \\
\hline KP $\ldots \ldots \ldots$ & 535,61 & 6 & 89,26 & 2,24 \\
\hline $\mathrm{K}_{\mathrm{L}} \mathrm{P}_{\mathbf{L}} \ldots \ldots$ & 18,22 & 1 & 18,22 & \\
\hline$K_{L_{3}} \mathrm{P}_{Q} \cdots \cdots$ & 0,68 & 1 & 0,68 & \\
\hline $\mathrm{K}_{\mathrm{Q}} \mathrm{P}_{\mathrm{L}} \ldots \ldots$ & 106,40 & 1 & 106,40 & 2,67 \\
\hline (+) $\mathrm{K}_{\mathbf{Q}} \mathrm{P}_{\mathrm{Q}} \quad \ldots \ldots$ & 402,89 & 1 & 402,89 & $10,11^{* *}$ \\
\hline NK $\ldots \ldots \ldots \ldots$ & 677,33 & 4 & 169,33 & \\
\hline$N_{\mathrm{L}} \mathrm{K}_{\mathrm{L}} \ldots \ldots$ & 68,88 & 1 & 68,88 & $4,25^{*}$ \\
\hline$(-) N_{L} K_{Q} \quad \ldots \ldots$ & 411,75 & 1 & 411,75 & $10,33^{* *}$ \\
\hline $\mathrm{N}_{\mathrm{Q}} \mathrm{K}_{\mathrm{L}}, \ldots$ & 192,51 & 1 & 192,51 & 4,83 \\
\hline $\mathrm{N}_{\mathrm{Q}} \mathrm{K}_{\mathrm{Q}} \ldots \ldots$ & 4,18 & 1 & 4,18 & \\
\hline NPK $\ldots \ldots \ldots$ & 439,82 & 12 & & \\
\hline $\mathrm{N}_{\mathrm{L}} \mathrm{P}_{\mathrm{L}} \mathrm{K}_{\mathrm{L}} \quad \cdots$ & 1,42 & 1 & 1,42 & \\
\hline resto NPK ..... & 438,40 & 11 & 39,85 & \\
\hline
\end{tabular}

York e Colwell (8) citam trabalhos de Prevot, nos quais êste outor determinou que na época de formação do fruto há grande translocação de nitrogênio das fôlhas para o fruto, havendo portanto grande necessidade de suprimento dêsse elemento no solo, para obtenção de boas colheitas.

Relatam algumas experiências de West, conduzidäs em Missis- 
sipi, nas quais foi verificado um diminuto aumento com a aplicação de cêrca de 18 ou 35 quilos por hectare de nitrogênio, quando empregado em um fertilizante completo. Citam ainda vários outros experimentos que mostram o pequeno aumento obtido pela aplicação de fertilizantes nitrogenados.

Gore (4) diz que aplicação de fertilizantes nitrogenados e potássicos, em amendoim da variedade Spanish, resultou em pequeno aumento de produção.

Concluindo, York e Colwell (8) dizem que, devido à confusão reinante na literatura, não é possível obter-se uma conclusão satisfatória com o emprêgo de fertilizontes nitrogenados em cultura de amendoim. Porém, existem dados suficientes para se crer na possibilidade da obtenção de respostas favoróveis à aplicação dêstes fertilizantes, quando os outros elementos estão presentes.

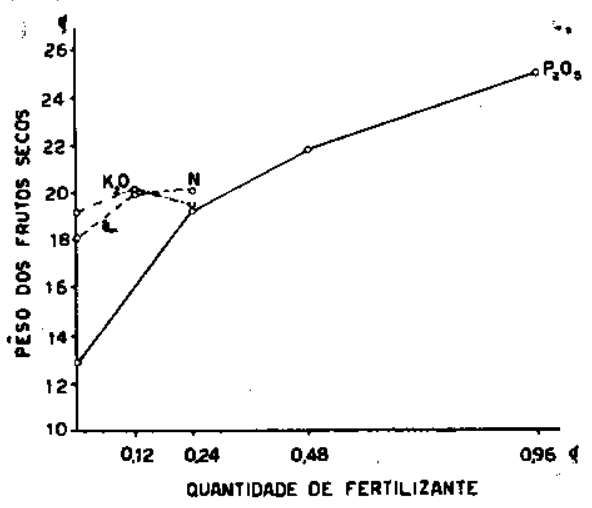

Figura 2. - Produções médias, por vaso de Mitscherlich, em gramas de frutos secos, obtidas em função dos doses dos elementos $\mathrm{N}, \mathrm{P}_{2} \mathrm{O}_{5}$ e $\mathrm{K}_{2} \mathrm{O}$ empregadas.

A aplicação de fertilizantes potássicos não causou qualquer aumento de produção, apesar de o solo possuir um teor médio nesse elemento.

Alguns autores $(3,8)$ mostram uma série de experiências em que $\circ$ potássio também não apresentou ação alguma. Mesmo em solos.cujo nível de potássio é considerado médio, o efeito dêsse fer- 
tilizonte foi de muito pequeno valor. Recomendam a aplicação de fertilizantes potássicos na cultura que antecede d̀ do amendoim e que êste deve ser plantado em rotação.

Das interações estudadas, N P não foi significativa. Já a interação $N$ K foi significativa a $5 \%$. Desta, a componente $N_{L} K_{Q}$ foi a mais importante, se bem que negativa. Da interação $P K$, o componente $\mathrm{P}_{\mathrm{Q}} \mathrm{K}_{\mathrm{Q}}$ foi também significativo.

Os efeitos do fósforo e do nitrogênio, que são os principais, foram aditivos. Podemos concluir que a melhor combinação dos fertilizantes nitrogenados e fosfatados seria a dosagem $N_{1} P_{3}$.

Pelos dados obtidos no presente experimento, pôde ser verificado que existe grande semelhança de reação aos mesmos elementos químicos, tanto para o dsenvolvimento das plantas (medido pela parte aérea em pêso sêco) como para a produção de frutos (medida pelo pêso dos frutos).

É provóvel que em condições de campo, em que partes de nitrogênio e potássio se perdem por lixiviação, reaçōes mais nítidas a êșses elementos possam ser obtidas.

\section{4 - CONCLUSŌES}

a) O fertilizante que proporcionou maior aumento de produção foi o fósforo, influindo favoràvelmente tanto no desenvolvimento da parte aérea como na produção dos frutos.

b) o nitrogênio foi o elemento que, após o fósforo, mais favoreceu o aumento de produção, tendo influído significativamente tanto na parte aérea como na produção do amendoim.

c) O potássio, ao contrário dos dois precedentes, não apresentou efeito algum com relação ao aumento de produção.

d) Pelos dados obtidos neste experimento pode-se concluir que a fórmula de adubação que melhores resultados produziu foi a $N_{1} P_{3}$, a qual equivale a 30 quilos de $\mathrm{N}$ e 240 quilos de $\mathrm{P}_{2} \mathrm{O}_{5}$ por hectare. 


\section{N-P-K FERTILIZER TEST WITH PEANUTS}

\section{SUMMARY}

The present test was carried out with peanut plants grown in Mitscherlich pots filled with the "terra-roxa-misturada" type of soil. Its objective was to determine the influence of the three major elements, viz. nitrogen, phosphorus, and potassium on the yield. A $3 \times 4 \times 3$ factorial design was employed, each treatment being replicated 3 times. Both the aeriol parts of the plants and the fruit were harvested separately and used for statistical analysis.

Fruit yield and weight of aerial parts showed similar responses to the treatments. Phosphorus increased the yield the most, followed by nitrogen; potash had no influence on yield. According to the results obtained the best formula was $N_{1} P_{3}$, corresponding to 30 and $240 \mathrm{~kg}$ of $N$ and $P_{2} O_{5}$ per hectore, respectively.

\section{LITERATURA CITADA}

1. BEATTIE, 1. H., POSS, F. W. \& HIGGINS, B. B. Growing Peanuts. Washington, D.C., U.S. Department of Agriculture, 1953. 28p. (Farmer's Bulletin n.o 2063)

2. CANECCHIO, V. (filho). Nova variedade de amendoim. Agronômico 8(1-2):[1]-2. 1956.

3. Estados Unidos. North Coroli_ultural Extension Service. Peanut production guide for North Corolina Farmers. Raleigh, 1953. 23p. (Extension Circular n. 0257$)$

4. GORE, U.R. Culture and fertilizer studies with peanuts. Experiment, Georgia Experiment Station, 1941. 19p. (Bulletin n. ${ }^{\circ}$ 209)

5. RODRIGO, P.A. Peanut culture in the Philippines. Philipp. J. Agric. 14:165-179. 1949.

6. SOUZA, O.F. \& CANECCHIO, V. (filho). Instruções para a cultura do amendoim. Campinas, Instituto agronômico, 1954. 4p. (Boletim n. ${ }^{\circ} 57$ )

7. VANDECAVEYE, S.C. Biological methods of determining nutrients in soil. In Kitchen, H.B., ed. Diagnostic tecniques for soils and crops. Washington, American Potash Institute, 1948. p. 199-230.

8. YORK, E.T. (jr) \& COLWELL, W.B. Soil properties, fertilization and maintenance of soil fertility. In The national fertilizer association, ed. The peanut The unpredictable legume. Woshington, D.C., 1951. p. 122-172. 